\title{
Reliability of III-V concentrator solar cells
}

\author{
Carlos Algora \\ Instituto de Energía Solar - Universidad Politécuica de Madrid, ETS.I. Telecomunicaciốn-Avda Complutense 38, 28040 Madizd, Spain
}

\begin{abstract}
A B S T R A C T
III-V concentrator solar cells are starting to be commercialized. However, no complete studies about their reliability have been carried out. A review about both the accelerated ageing tests and real time tests developed till now is presented. A proposal about the required tests is also done. In this stage, the tests show that III-V concentrator cells are robust devices with MTTFs well over the expected ones (30 years),
\end{abstract}

\section{Introduction}

In recent years, significant advances have been made in the field of [II-V concentrator solar cells, achieving peak efficiencies of $32.6 \%$ at 1000 suns for a double junction solar cel] [1] and $41.6 \%$ at 364 suns for a triple junction solar cell [2]. These satisfactory efficiency results have crystallized into the first commercial ventures of Multi Junction Solar Cell (MJSC)-based Concentration PhotoVoltaic (CPV) systems [3] with the aim of achieving a notable reduction of the solar electricity cost. At present, there is a total amount of more than 6.5 MW of II]-V MJSC-based CPV systems installed in the world [4].

In parallel with such rapid evolution, a new qualification standard, namely the IEC62108, has been developed [5] in which the procedure for qualifying CPV systems and assemblies is described. However, such standard does not consider specifically concentrator solar cells and there is no other that defines their failure condition or power degradation. In addition, qualification is not the same as reliability. Qualification is a pass/fail testing, on the contrary, reliability testing forces the failure to determine when and why it happens.

In order to obtain CPV modules with a well-defined warranty to the customer, it is necessary to demonstrate the reliability of [I]-V high concentrator MJSCs. It is well known that silicon flat plate modules are very reliable systems capable of withstanding 25 years in field operation [6]. Nowadays, warranties offered by the manufacturers are about 25 years, but this value is expected to increase until 30 years in the near future [7]. If CPV systems are expected to be competitive with silicon flat plate modules, they must be capable of reaching similar warranties. Nevertheless, there are still many open questions regarding the reliability of MJSCs operating at high concentration that should be answered in order to give such warranty.
Although there are some preliminary results regarding the degradation of these solar cells [8-11], there is not enough accumulated experience to evaluate their reliability. The study of degradation is of great importance but it is important to keep in mind that reliability is a completely different issue [12]. For instance, in terms of degradation, typical studies found in PV related conferences consist in a set of solar cells introduced in a climatic chamber, the temperature is increased and the cells are biased to a specific current level, the number of failures is registered and the Mean Time to Failure (MTTF) is calculated with the following expression:

$M T T F=\sum_{i=1}^{N} \frac{t_{F i}}{N_{F}}$

where $t_{F i}$ is the time of every failure and $N_{F}$ is the number of failures. In this case, the test is just a degradation limited in time study. In summary, most of the degradation tests only evaluate solar cell power in a very aggressive and disperse way. The objective of these tests is to compare qualitatively in a short period of time the new generations of MJSCs without any reliability analysis.

The problem is that this kind of tests does not establish a correlation between the test time and the lifetime of the device. With degradation limited in time, it is not possible to determine in which patticular period of the classical bath-tube cutve (decreasing, constant or increasing failure time) is the device working at [12]. Unfortunately, CPV as a recent discipline has not the tradition of pure reliability including all its protocols, statistical methods, etc. Therefore, it is very common within the CPV field to fiend the use of sentences such as "reliability analysis" with the simple meaning of a set of degradation experiment in order to know if a given cell, system, etc. shows infant failures.

In order to clarify how a reliability test within the CPV field should be carried out, it is important to consider the following points: 


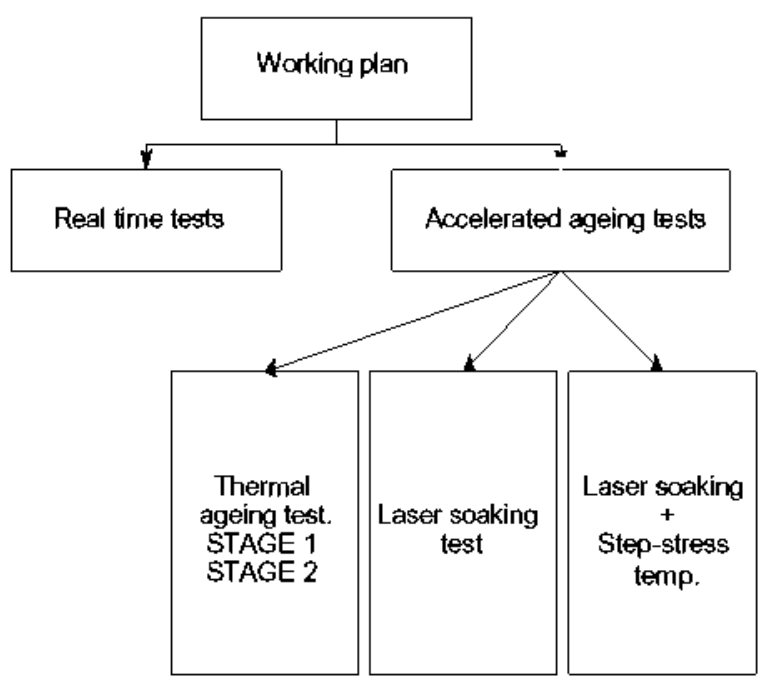

Fig. 1. Working plan for assessing the reliability of III-V concentrator solar cells (taken from [26]).

1. To define what reliability is. A good definition is that reliability is the probability that a component part, equipment, or system will satisfactorily perform its intended function under given circumstances, such as environmental conditions, limitations as to operating time, and frequency and thoroughness of maintenance for a specified period [13].

2. To establish a test procedure in which the following tasks should be taken into account: (a) to define a failure criterion; (b) to apply a stress factor; (c) to carty out statistics, with the aim of getting the activation energy, the acceleration factor and the main reliability functions (reliability $(R(t))$, failure rate $(\lambda(t))$ and MTTF).

Summarizing, the CPV reliability testing should be directed not only to determine how long devices are going to live, but also the way in which these devices are going to live. In other words, reliability is also interested in knowing the probability distribution of failure in nominal conditions of operation [12].

A working plan has been defined to carry out the reliability assessment on GaAs single-junction solar cells as Fig. 1 shows $[14,12]$. This plan which can be easily extended to MJSCs consists of real time tests and accelerated ageing tests. The accelerated tests allow to shorten the time to evaluate the reliability of a device; the real time tests allow to determine if the stress factor introduces failure modes that would never happen in real operation.

\section{The similarities with High Bright Light Emitting Diodes (HB-LEDs)}

One of the most suitable approaches for designing and manufacturing III-V MJSCs able to efficiently operate at ultra high concentrations ( 1000 suns or more) is to look at the LEDs. So we call it the "LED-like approach" [15]. In fact, the approach of manufacturing ]II-V MJCs in a similar manner to that of LEDs is being identified as one of the most solid ones for having success in reducing PV costs $[16,17]$.

The increasing interest in a new illumination concept with solid state lighting technology, namely LEDs, is currently valuing the LED industry at about $\$ 2.5$ bn, that is, similar to PV. Because both technologies are based on III-V semiconductors, the paralle] growth of III-V PV and LED industries could help in reducing costs for both.

Although the boom in LED illumination is very recent, the "LEDlike approach" for [I]-V MJSCs has not been proposed so recently.
In fact, the use of optoelectronic technologies together with a decrease in the size of concentrator GaAs solar cells to about $1 \mathrm{~mm}^{2}$, as a way of reducing the cost of PV technology was proposed in 1997 [18]. When the MJSCs operate at concentrations in the range of 1000 suns, the advantages of a solar cell size of about $1 \mathrm{~mm}^{2}$ are $[19,20]$ : (a) higher solar cell efficiency as a consequence of the trade-off between series resistance and recombination at the perimeter, (b) better heat extraction and (c) lower cost of the optics and encapsulation. From then on, several laboratories and pilot production lines have followed the "LED-like approach".

The biggest overlapping issues between LEDs and [II-V MJSCs are [21]:

- Need for good crystalline quality of [l]-V semiconductor layers.

- Encapsulation.

- Antireflecting coating and passivation.

- Automated visual inspection.

- Thermal-mechanical modelling.

- Wafer bonding and substrate release.

- Reliability physics.

Consequently, the processes in the manufacture of HB-LEDs can be considered when manufacturing [I]-V MJSCs. The adaptation of LED manufacture to that of JII-V cells can be summarized in the following steps:

- MOVPE growth of the semiconductor structure.

- Front grid definition through photolithography.

- Front and back metallic contacts: thermal or e-gun evaporation plus contact alloy.

- ARC deposition.

- Assembling and encapsulation: wire-bonding for the front, conductive epoxy or solder paste for back plus the use of other techniques, such as dicing, pick and place, etc.

Different aspects in the manufacture of MJSCs following the LEDlike approach can be seen in Fig. 2. A direct consequence derived from using both similar LED's semiconductor materials and manufacturing steps is the achievement of similar prices for the M]Cs [22].

Considering all these similarities between HB-LEDs and small size ]II-V concentrator M]SCs, an analysis to determine to what extent ][I-V high concentration solar cells are stressed in comparison with LEDs has been carried out in a previous work [23]. As a result, it has been concluded that solar cells handle lower current densities than LEDs (about $15 \mathrm{~A} / \mathrm{cm}^{2}$ for MJSCs operating at 1000 suns in comparison with about more than $100 \mathrm{~A} / \mathrm{cm}^{2}$ for the HB-LEDs) and that solar cells are also expected to operate at their maximum power point for most of their useful life (i.e. the point at which the maximum fraction of the power is delivered to a load and thus the minimum fraction of the power is internally available for degradation).

In the same paper [23], it was shown that in this situation, there is a higher stress on series resistance and a lower one on the junction. Therefore, a significant effort must be made to reduce the series resistance in order to decrease the degradation of the solar cells. The effect of temperature is less severe in MJSCs than in HB-LEDs. It was also concluded that encapsulating and protecting the solar cells against moisture is a must for obtaining highly reliable devices. Finally, a theoretical prediction showed that a MTTF as high as $10^{5} \mathrm{~h}$ (this is equivalent to 34 years assuming $8 \mathrm{~h}$ of average operation per day) could be reached for these solar cells [23].

\section{First reliability analyses based on temperature stress tests}

After this prediction, the first reliability analysis derived from a stress-temperature ageing test performed on a [I]-V high 

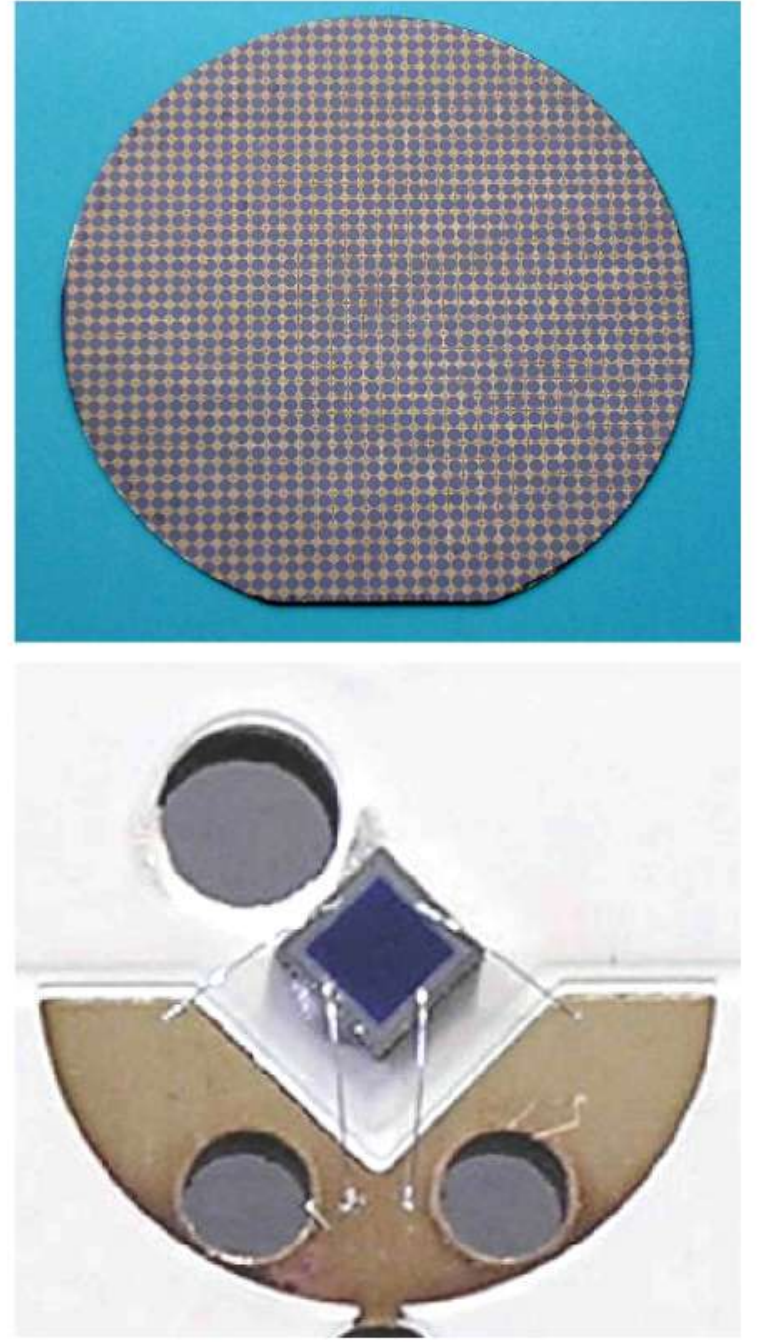

Fig. 2. (Top) A 2-in. wafer containing about $1000 \mathrm{GaInP} / \mathrm{Galn} A \mathrm{As} / \mathrm{Ge}$ triple junction solar cells manufactured at IES-UPM (photo: courtesy of J.R. González). (Bottom) A photograph of a $1 \mathrm{~mm}^{2}$ concentrator IIl-V solar cell encapsulated following the "LED-like approach" on the base of the module (courtesy of Isofotón).

concentrator solar cells was carried out in [24]. Unprotected single-junction GaAs solar cells were subjected to temperature stepstress ageing test in climatic chambers. Working conditions were simulated by forward biasing the $1 \mathrm{~mm}^{2}$ solar cells at the same current level $\left(250 \mathrm{~mA}\right.$, i.e. $\left.25 \mathrm{~A} / \mathrm{cm}^{2}\right)$ they would handle at the operating concentration (i.e. 1000 suns). Dark I-V curves were routinely registered during the test at the temperature of every step $\left(90,110,130\right.$ and $150^{\circ} \mathrm{C}$, respectively). By using the method described in [25], the experimental data recorded for the dark I-V curve were used to reproduce the illumination curve.

Data were analyzed according to the Weibull reliability function. This analysis yielded a lower value of the MTTF of $2.02 \times$ $10^{5} \mathrm{~h}$ (i.e. about 69.2 years assuming $8 \mathrm{~h}$ of average operation per day in a year) for a confidence interval of $90 \%$. The activation energy was not determined in this test, but the selected value for the calculation of the acceleration factor $(0.9 \mathrm{eV})$ can be considered to be a low value if compared to the literature for similar degradation mechanism in optoelectronic devices [24].

The reliability at 25 years was higher than $65 \%$ (see Fig. 3). This is a low value for a solar cell, but that work dealt with devices manufactured in a research laboratory, therefore it could be considered as a promising result. Besides, the failure rate in the initial stage decreased very steeply. Then, the failure rate trends asymptotically
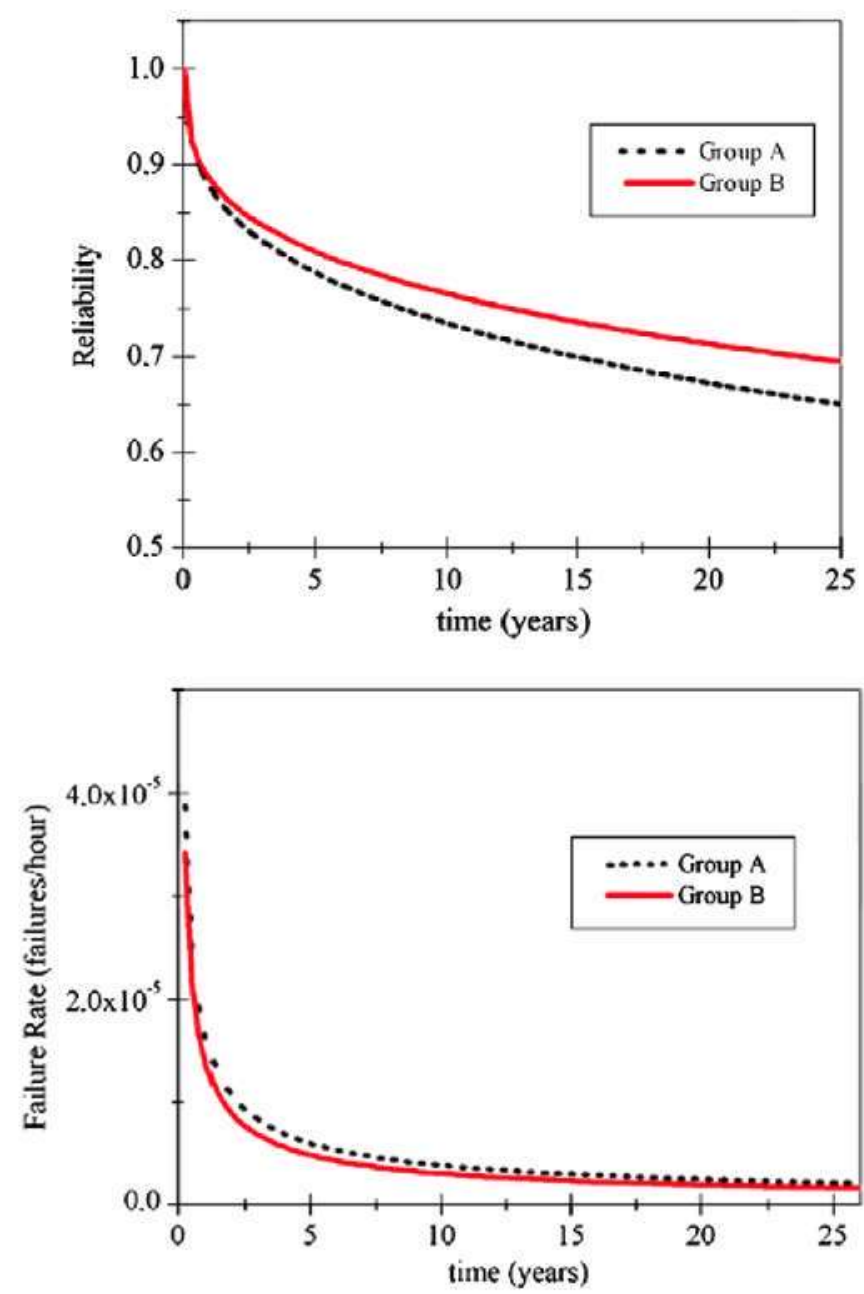

Fig. 3. Reliability and failure rate estimations for a period of 25 years of operation of the GaAs single-junction solar cells operating at 1000 suns, obtained in [24].

to a saturation value as can be seen in the bottom of Fig. 3 . The failure rate estimation at 25 years is $1.67 \times 10^{-6}$ failures/year, which is a promising result, mostly bearing in mind that the experiment was performed on uncoated and bare devices. In this sense, the origin of degradation was shown to be related with the appearance of short-circuits at the perimeter of the devices [24].

A recent work has tried to circumvent the failure originated at the perimeter by protecting the cells with a transparent cover [26]. Once again small size (about $1 \mathrm{~mm}^{2}$ ) GaAs single-junction solar cells were tested in order to compare them with the study in [24] but now the cells were coated with silicone to protect their perimeter which, in addition, reproduces the real situation of a cell inside a secondary optics in a concentrator.

The main conclusions of that work show that perimeter protection seems to be a good way of enhancing the reliability of the solar cells because no degradation is found related to short-circuits at the perimeter. Besides, the low degradation suggests a MTTF value one order of magnitude larger than the one obtained in the thermal stress step test [24] where the perimeter was uncoated. In the work of [26] a simple method based on a 3-D distributed model of the solar cells has been used for the failure analysis [27] which was also employed in [24]. As Fig. 4 shows, the degradation experimented by the solar cells is compatible with a decrease in the shunt resistance at the perimeter (from $1.0 \times 10^{5}$ to $1.8 \times 10^{1} \Omega$ / $\mathrm{cm}$ ) for the experiment described in [24] while in the work of [26] the degradation is much lower and compatible with an increase of the $J_{02}$, per $(2 k T$-recombination current density at the 

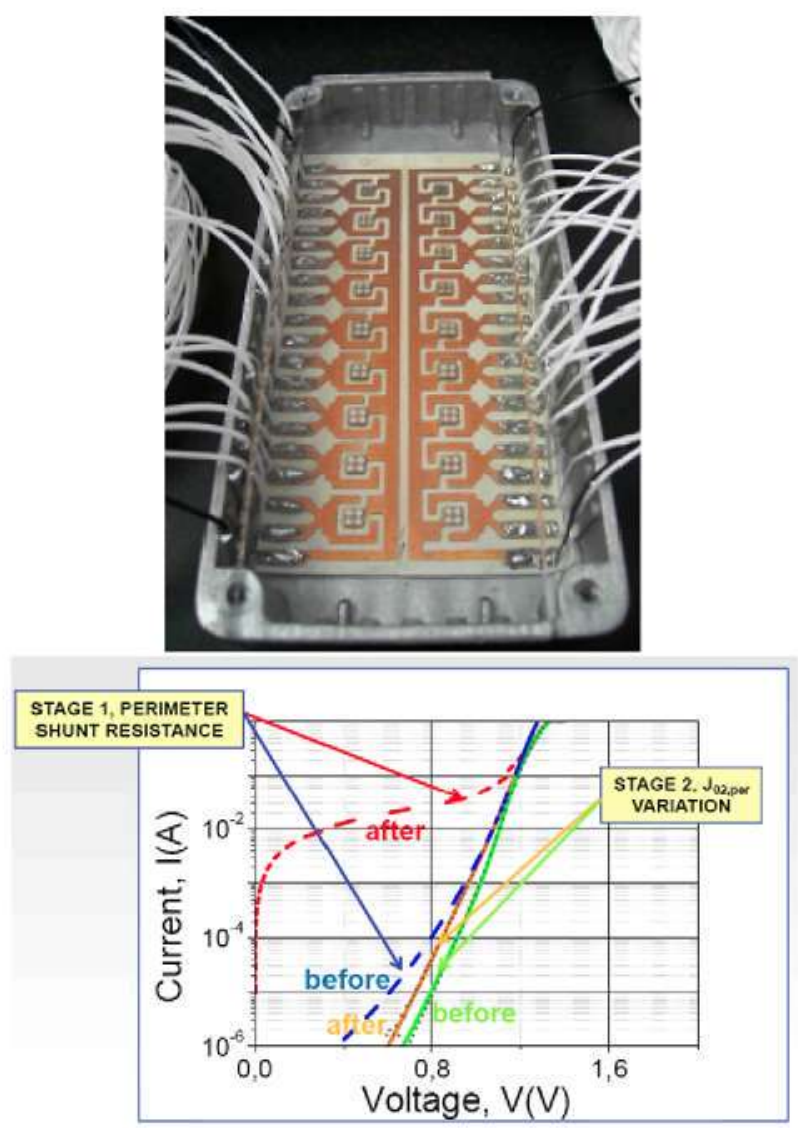

Fig. 4. (Top) GaAs solar cells encapsulated on a DBC substrate and covered with silicone [26]. The caption shows the wiring inside the climatic chamber before the beginning of the test. (Bottom) Dark I-V curves of two different cells before and after de degradation process. Solar cell of stage 1 corresponds to the experiment of [24] while solar cell of stage 2 corresponds to the experiment of [26].

perimeter) from $2 \times 10^{-12}$ to $8 \times 10^{-12} \mathrm{~A} / \mathrm{cm}$ and without short-circuits at the perimeter.

A step forward has been carried out in [28] where again small size GaAs solar cells protected with silicone where degraded at different temperatures and injection currents. At an injected current equivalent to 1050 suns and a temperature of $150^{\circ} \mathrm{C}$, a power degradation of $4 \%$ was observed after around $2000 \mathrm{~h}$ of accelerated test. Test is running but considering a nominal operation temperature of the cells of $65^{\circ} \mathrm{C}$, the test at $150^{\circ} \mathrm{C}$ implies an acceleration factor of more than 800 . Therefore, those solar cells operating $8 \mathrm{~h} /$ day at 1050 suns would experiment a power degradation of $4 \%$ in more than 550 years.

In the same work, solar cells were also tested by injecting a current equivalent to 700 suns. The degradation at 1050 suns was four times higher than at 700 suns. The final objective of the work of Ref. [28] is the determination of the MTTF and $R(t)$ function. For doing so, it is necessary to analyse the power evolution at other temperatures in order to validate the Arrhenius law.

\section{Additional accelerated ageing tests}

Consequently, III-V MJSCs operating at ultra high concentration seem to be very robust devices with much longer MTTFs than HBLEDs because operating conditions of solar cells are less demanding than those of LEDs. However, the results presented in $[24,26,28]$ are based on tests in which the injected current does not cross all the parts of the device such as in photogeration conditions happens. Besides, there is no stress caused by illumination.

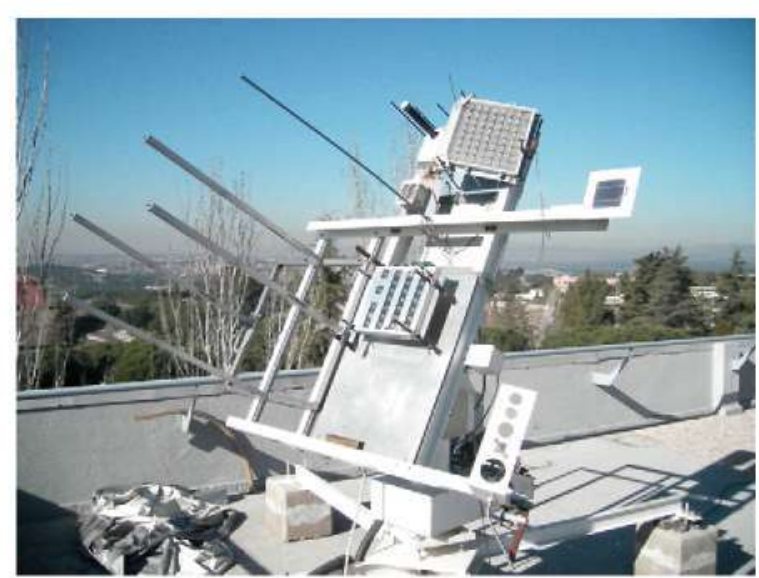

Fig. 5. Two-axis sun tracker installed on the flat roof of the Instituto de Energía Solar - Universidad Politécnica de Madrid (IES-UPM).

Therefore, additional type of test set must be developed. More specifically, laser soaking plus temperature tests must be properly defined and carried out [12].

In spite that the aforementioned works have established a proper methodology, failure criteria, etc. for determining the reliability of cells, the experiments have been carried out on GaAs single-junction cells. Accordingly, it is necessary to develop similar tests with MJSCs in order to detect anomalous origins of failure such as those detected when germanium is the substrate of the MJSCs [29].

Reliability issues related with the receiver (solar cell inside the optical concentrator) include chip (solar cell) attachment, soldering voids, heat dissipation, light homogenization, etc. Degradation tests developed on these parts surrounding the MJSC such as those described in $[30,31]$ are required.

\section{Real time tests}

Finally, these accelerated ageing tests must be complemented with real time tests in which the different parts of the module and specially the concentrator MJSCS must be analyzed. To our knowledge, the first attempt has been carried out in [32] where a statistical model for assessing the reliability of a CPV module based on degradation data was presented. The model was applied to a CPV module manufactured specifically with the purpose of assessing its reliability.

For that test, a module composed of 32 GaAs single-junction solar cells with TIR (Total Internal Reflection) [33] optics was used. The module was outdoor-tested for 7 months. This CPV module featured an assembly that allowed independent electrical access to every receiver contained therein. The evolution of each of these receivers was followed independently, avoiding the "hiding effect" in performance degradation that results from a single measurement of a series or parallel configuration in a conventional assembly. The module was mounted on a two-axis sun tracker installed on the flat roof of IES-UPM (see Fig. 5).

A data acquisition system was developed to periodically measure I-V curves of the solar cells. Irradiance and wind speed were obtained from the IES Meteorological Station [34]. The data acquisition system periodically recorded the following information:

- Illumination I-V curves of each individual solar cell every $15 \mathrm{~min}$ from 10:00 h to $17: 00 \mathrm{~h}$.

- Dark I-V curves for each individual solar cell once a day at 02:00 h.

- Direct irradiance and ambient temperature data synchronized with the I-V curve measurement. 


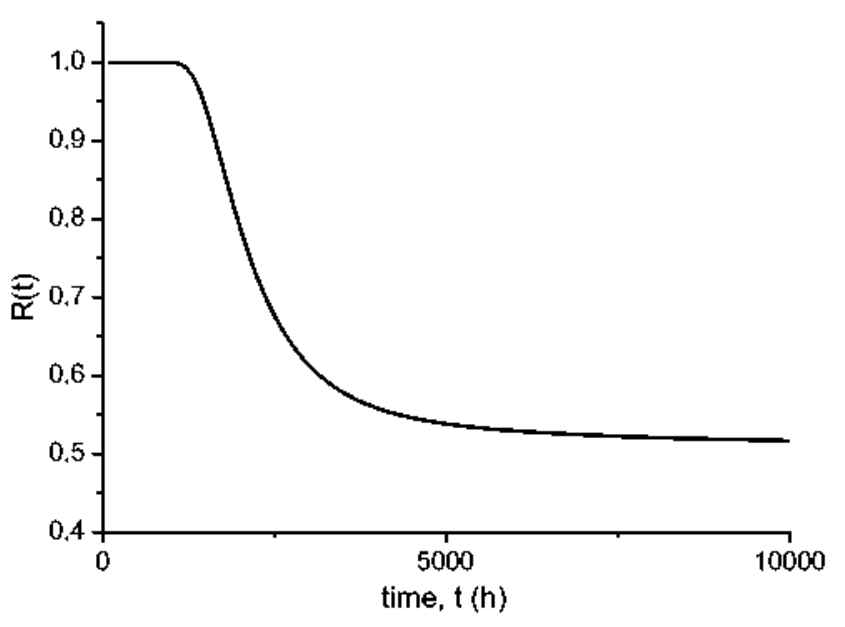

Fig. 6. Time-dependent reliability function (taken from [32]).

Dark and illumination I-V curves were recorded to follow the evolution of the solar cells. The temperature of the modules was measured at the back of the device [35].

The illumination l-V curves were normalized using the equations proposed by the lnstituto de Sistemas Fotovoltaicos de Concentración (ISFOC) [36]. The normalized curves obtained by the method described were used to follow the power output of the solar cells and thus to obtain the main reliability functions [32].

lt was observed that the $I_{s c}$ suffered a strong decrease with time, whereas the variation in $V_{o c}$ was not significant. The resulting loss in power output was produced by degradation of the optics (bad sealing and misalignment). Optical degradation was evaluated by means of the I-V curves under illumination and visual inspection of the module. Solar cells did not suffer degradation during the test, as was determined by the analysis of the dark l-V curves.

The failure rate of the experimental module increased with time according to a degradation process. The MTTF (derived from the reliability function, see Fig. 6) yielded a value of $7080 \mathrm{~h}$, which is extremely low compared to the expected lifetime of a photovoltaic system ( $\sim 25$ years). The manual assembly of the module in order to allow the independent access to each receiver was identified as the main reason for such a low value of the MTIF.

It is important to point out that the main purpose of that paper [32] was to present a model to determine the reliability and to provide a method to calculate the main reliability functions of CPV modules. As an example, the model presented in that work has been applied to a specific CPV modules. Therefore, the values of the main reliability functions are not significant. Once the way is shown, more tests must be done in the different existing CPV systems. In this sense, the valuable work developed at ISFOC (Puertollano, Spain) [37] on the global performance and reliability of complete systems seems to be key in order to get confidence in the III-V MJSCs-based CPV technology.

\section{Acknowledgements}

The author would like to thank Prof. Manuel Vázquez, Dr. José Ramón González and Mr. Neftalí Núinez for their interest comments about this paper. The author also expresses his gratitude to the current and former members of the Group of ][]-V Semiconductors of the Solar Energy Institute of the Technical University of Madrid (IES-UPM) for their close collaboration and involvement in the subjects covered in this paper.

This work has been supported by the Spanish Ministerio de Educación y Ciencia with the CONSOLIDER-INGEN]O 2010 program by means of the GENESIS FV project (CSD2006-004). The Spanish Ministerio de Ciencia e Innovación has also contributed with the SIGMASOLES project (PSS-440000-2009-30) and with the projects with references TEC2008-01226 as well as the Comunidad de Madrid under the NUMANClA II programme (S2009/ENE1477).

\section{References}

[1] Algora C, Rey-Stolle I, García I, Galiana B, Espinet P, Baudrit M, et al. A dual junction solar cell with an efficiency of $32.6 \%$ at 1000 suns and $31.0 \%$ at 3000 suns. In: 5th International conference for the generation of electricity. Palm Desert; November 2008.

[2] King R, et al.Band-gap-engineered architectures for high-efficiency multijunction concentrator solar cells. In: 24th European photowoltaic solar energy conference and exhibition, Hamburg; September 2009.

[3] Wilming $W$. Bringing the sun into focus. Sun \& wind energy 12/2009;2009, p. 98-104.

[4] Rubio F. ISFOC, private communication.

[5] International Electrochemical Commission (IEC). Concentrator photovoltaic (CPV) modules and assemblies - design qualification and type approval; 2007.

[6] Skoczek A, Sample T, Dunlop ED. The results of performance measurements of field-aged crystalline silicon photovoltaic modules. Prog Photovolt: Res Appl 2009;17(April):227-40.

[7] Wohlgemuth JH, Cunningham DW, Nguyen AM, Miller J. Long term reliability of PV module. In: 20 th European photovoltaic solar energy conference, Barcelona, 5pain; 2005, p. 1942-6.

[8] Rey-Stolle I, Algora C. High-irradiance degradation tests on concentrator GaAs solar cells. Prog Photovolt: Res Appl 2003;11:249-54.

[9] Rey-Stolle I, Algora C. Reliability and degradation of high concentrator GaAs solar cells. In: 17th European PV solar energy conference, Munich; 2001.

[10] Araki K. Kondo M. Uomizi H, Kemmoku Y, Egami T. Hiramatsu M, et al. A 28\% efficient, $440 \mathrm{x}$ and $200 \mathrm{Wp}$ concentrator module. In: 19th European photovoltaic solar energy conference; 2004.

[11] Sherif RA. et al. Pilot production of multijunction CPV solar cells. In: 4th International conference on solar concentrators for the generation of electricity or hydrogen; 2007.

[12] González ]R, Algora C, Vázquez M, Núnez N, Rey-Stolle l. Strategy for assessing the reliability of III- $V$ concentrator Solar cells: working plan review and first results. In: Proceeding of the 5th international conference on solar concentrators, Palm Desert, CA (USA); 2008. ISBN: 978-0-615-29119-2.

|13| Sybil P. Parker. McGraw-Hill dictionary of scientific and technical terms, 6th ed. The McGraw-Hill Companies, Inc; 2002. ISBN: 007042313X.

|14| José Ramón González Ciprian. Fiabilidad de células solares de concentración de semiconductores III-V. Doctoral Thesis, Universidad Politécnica de Madrid; 2008.

|15| Algora C. et al. Strategic options for a lED-like approach in III- $v$ concentrator photovoltaics. In: Proceedings of the 2006 IEEE 4th world conference photov energy conv, Hawaii (USA); 2006, p. 741-4.

|16| Kurtz $\$$. Synergies connecting the photovoltaic and solid-state lighting industries. In: NCPV and solar program review meeting; 2003. p. 315-8.

|17| Purvis G. LED and nano could boost compound photovoltaics, lll-Vs review. Adv Semicond Mag 2004;17(6):36-9.

|18| Algora C. Día2 V. Guidance for reducing PV costs using very high concentrator GaAs solar cells. In: Proceedings of 14th European photovoltaic solar energy conference, Barcelona, Spain; 1997. p. 1724-7.

|19| Algora C. Díaz V. Miñano JC, luque A. Cost reduction in concentrator GaAs solar cells based PV plants: going from photovoltaics to optoelectronic processing. In: Proceedings of 2 nd world conference on PV solar energy conversion, Vienna, Austria; 1998. p. 2225-8.

[20] Algora C. Universidad Politécnica de Madrid. High efficiency photovoltaic converter for high light intensities manufactured with optoelectronic technology. US2002/0170592A1.

[21] González JR, Rey-Stolle I, Algora C. Degradation mechanisms and reliability testing of high concentrator lll- $V$ solal cells. Lessons learned from optoelectronics. In: Proceedings of the 19th European photovoltaic solar energy conference; 2004. p. 3618-21.

[22] Algora $C$. The importance of the very high concentration in 3rd generation solar cells. In: Martí A, Luque A, editors. Chapter 6 of the book "3rd generation photovoltaics for high efficiency through full spectrum utilization". Institute of Physics Publishing, Bristol (UK); 2004.

|23| Vázquez M. Algol'a C. Rey-Stolle l, González JR. Ill-V concentrator solar cell reliability prediction based on quantitative LED reliability data. Prog Photovolt: Res Appl 2007;15(6).

|24| Gonzalez JR, Vazquez M, Nunez N. Algora C, Rey-Stolle I, Galiana B. Reliabilicy analysis of temperature step-stress tests on III-V high concentrator solar cells. Microelectron Reliab 2009;49:673-80.

[25] Anton I, Sala G, Heasman K, Kern R, Bruton TM. Performance prediction of concentrator solar cells and modules from dark $\mathbf{l} V$ characteristics. Prog Photovolt: Res Appl 2003;11:165-78.

[26] González JR, Vázquez M, Núñez N, Algora C, Espinet P. Reliability improvement in III-V concentrator solar cells by means of perimeter protection. In: Proceedings of the CPV6. Feiburg. Germany, in press. 
|27| Espinet P. Algora C, González JR. Núnez N. Vázquez M. Failure mechanism analysis in temperature stress tests on III-V ultra-high concentrator solar cells using a 3D distributed model. Microelectron Reliab. in press.

[28] Núñez N, Vázquez $M$, González JR, Algora C, Espinet P. Novel accelerated testing method for $\mathrm{lll}-\mathrm{V}$ concentrator solar cells. Microelectron Reliab, in press, doi: 10.1016 j.microrel.2010.07.085.

[29] Schone J, Peharz G, Hoheysel R, Siefer G, Guter W, Dimroth F, et al. Impact of thermal cycles on the material quality of metamorphic III- $V$ solar cell structures. In: Proceedings of the 23rd EUPSC Valencia, Spain; 2008.

|30| Bosco N. Sweet C. Kurtz S. Reliability testing the die-attach of CPV cell assemblies. In: Proceedings of the 34th JEEE photovoltaic specialists conference, 7-12 June 2009, Philadelphia, Pennsylvania. Piscataway, NJ: Institute of Electrical and Electronics Engineer's, lnc. (IEEE); 2009. p. 00091722 .
[31] Buie D. Hofman R, Blumenfeld P. Foresi J. Nagyvary J. Dempsey C. A critique of Emcore's third generation CPV system. In: Proceredings of the 6th international conference on concentrating photovoltaic systems, Freiburg. Germany, in press.

[32] González JR. Vázquez M. Algora C. Núnez N. Real-time reliabilicy test for a CPV module based on a power degradation model. Prog Photovolt, in press.

[33] Terao A, Mulligan WP, Daroczi SG, Pujol OC, Verlinden P], Swanson RM, et al. A mirror-less design for micro-concentrator modules. In: IEEE 28 th photovoltaic specialist conference; 2000. p. 1416-9.

[34] <http://helios.ies-def.upm.es/s.

[35] Systems and instruments integration group of IES-UPM. Private communication.

[36] <http://www.icmf.es/icmf/ISFOC/PLIEGOCONDICIONES_Esp.pdfs.

[37] <http://wwwisfoc.com/s. 